\title{
Interaction between cardiovascular risk factors and body mass index and 10-year incidence of cardiovascular disease, cancer death, and overall mortality
}

Running title: Cardiovascular risk factors and body mass index

Maria Barroso $^{a, b}$, Albert Goday ${ }^{\mathrm{c}, \mathrm{d}, \mathrm{e}}$, Rafel Ramos ${ }^{\mathrm{f}, \mathrm{g}}$, Alejandro Marín-Ibañez Maria Jesús Guembe ${ }^{\mathrm{i}, \mathrm{j}}$, Fernando Rigo ${ }^{\mathrm{k}}$, Maria José Tormo-Díaz ${ }^{1, m, n, o}$, Conchi Moreno-Iribas $^{\mathbf{p}, \mathbf{q}, \mathbf{r}}$, Joan Josep Cabrés, Antonio Segurat, Jose Miguel Baena-Díez ${ }^{\mathrm{a}, \mathrm{b}}$, Agustín Gómez de la Cámara, ${ }^{0, u}$ José Lapetra ${ }^{\mathrm{d}, \mathrm{v}}$, Miquel Quesadaf, María José Medranow $^{w}$, Jesús Berjón ${ }^{\mathrm{i}, \mathrm{r}}$, Guillem Frontera ${ }^{\mathrm{k}}$, Diana Gavrila ${ }^{\mathbf{0}, \mathbf{x}}$, Aurelio Barricarte $^{\text {o,p,q, }}$, Josep Basora ${ }^{y}$, José María García ${ }^{t}$, Manel García-Lareo ${ }^{\text {b }}$, David

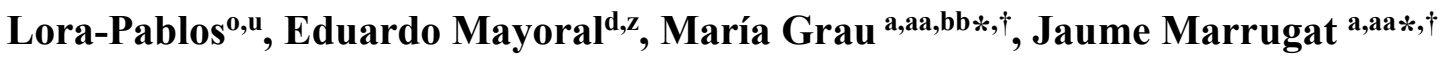
on behalf of the FRESCO Investigators

${ }^{a}$ REGICOR Study Group - Cardiovascular Epidemiology and Genetics, IMIM-Hospital del Mar Research Institute, Barcelona, Spain

${ }^{b}$ Primary Care Center La Marina and Primary Health Care Research Institute Jordi Gol, Catalan Institute of Health, Barcelona, Spain

${ }^{c}$ Parc de Salut Mar, Barcelona, Spain

${ }^{d}$ Consortium for Biomedical Research in Obesity and Nutrition (CIBEROBN), Spain

${ }^{e}$ Departament de Medicina, Universitat Autònoma de Barcelona, Spain

${ }^{f}$ Family Medicine Research Unit and Primary Health Care Research Unit Institute

Jordi Gol, Catalan Institute of Health, Girona, Spain

${ }^{g}$ University of Girona, Spain

${ }^{h}$ San Jose Norte Health Centre, Zaragoza, Spain

${ }^{i}$ Vascular Risk in Navarra Research Group (RIVANA), Health Department, Navarra Government, Pamplona, Spain

${ }^{j}$ Knowledge Planning, Evaluation and Management, Health Department, Navarra Government, Pamplona, Spain

${ }^{k}$ Cardiovascular Group of Balearic Islands (REDIAP-IBSALUT), Palma de Mallorca, Spain

${ }^{l}$ Murcian Health Departament, Murcia, Spain

${ }^{m}$ University of Murcia, Spain; ${ }^{n}$ Murcian Institute of Biomedical Research (IMIMB),

Murcia, Spain;

${ }^{\circ}$ Consortium for Biomedical Research in Epidemiology and Public Health

(CIBERESP), Spain

${ }^{p}$ Navarre Public Health Institute, Pamplona, Spain

${ }^{q}$ Research Network for Health Services in Chronic Disease (REDISSEC), Pamplona, Spain

${ }^{r}$ Navarra Hospital, IdiSNA-Navarra Institute for Health Research, Pamplona, Spain 


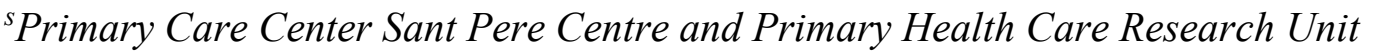
Institute Jordi Gol, Catalan Institute of Health, Reus-Tarragona, Spain

${ }^{t}$ Health Science Institute, Department of Health and Social Affairs, Castile - La

Mancha Government, Talavera de la Reina, Spain

${ }^{u}$ Clinical Research Department, Hospital 12 Octubre Research Institute, Madrid, Spain

${ }^{v}$ Department of Family Medicine, Research Unit, Primary Care Division of Seville,

Spain

${ }^{w}$ Carlos III Health Institute, Madrid, Spain; ${ }^{x}$ Health and Consumers Department,

Murcia Government, Murcia, Spain

${ }^{y}$ Primary Health Care Research Unit Institute Jordi Gol, Catalan Institute of Health,

Reus-Tarragona, Spain

${ }^{z}$ Diabetes Strategy, Andalusia Health Service, Sevilla, Spain

${ }^{a a}$ CIBERCV CIBER de Enfermedades Cardiovasculares, Spain

${ }^{b b}$ University of Barcelona, Spain

$\dagger$ Both authors have equally contributed.

A full roster of FRESCO Investigators can be found at www.regicor.org/fresco_inv.

*Corresponding author: Maria Grau (mgrau@imim.es) or Jaume Marrugat

(jmarrugat@imim.es), Research Group on Cardiovascular Epidemiology and Genetics,

IMIM-Hospital del Mar Medical Research Institute, Barcelona, Spain. Tel +34

933160710

Abstract word count: 246

Main text word count: 3102 


\begin{abstract}
The effect of above-normal body mass index (BMI) on health outcomes is controversial because it is difficult to distinguish from the effect due to BMI-associated cardiovascular risk factors. The objective was to analyze the impact on 10-year incidence of cardiovascular disease, cancer deaths and overall mortality of the interaction between cardiovascular risk factors and BMI. We conducted a pooled analysis of individual data from 12 Spanish population cohorts with 10-year follow-up. Participants had no previous history of cardiovascular diseases and were 35-79 years old at basal examination. Body mass index was measured at baseline being the outcome measures ten-year cardiovascular disease, cancer and overall mortality. Multivariable analyses were adjusted for potential confounders, considering the significant interactions with cardiovascular risk factors. We included 54,446 individuals (46.5\% with overweight and $27.8 \%$ with obesity). After considering the significant interactions, the 10-year risk of cardiovascular disease was significantly increased in women with overweight and obesity [Hazard Ratio=2.34 (95\% confidence interval: 1.19-4.61) and
\end{abstract} 5.65 (1.54-20.73), respectively]. Overweight and obesity significantly increased the risk of cancer death in women [3.98 (1.53-10.37) and 11.61 (1.93-69.72)]. Finally, obese men had an increased risk of cancer death and overall mortality [1.62 (1.03-2.54) and 1.34 (1.01-1.76), respectively]. In conclusion, overweight and obesity significantly increased the risk of cancer death and of fatal and non-fatal cardiovascular disease in women; whereas obese men had a significantly higher risk of death for all causes and for cancer. Cardiovascular risk factors may act as effect modifiers in these associations. Keywords: Body mass index, Cardiovascular Disease, Epidemiology, Mortality, Neoplasms, Obesity 


\section{Introduction}

Obesity is a worldwide public health problem due to its high prevalence, the epidemic increase observed in recent decades, and the associated diseases (GBD 2015 Obesity Collaborators, 2017; Finucane, 2011; Guh, 2009). The World Health Organization (WHO) reports that more than 1.9 billion adults were overweight in 2014, and more than 600 million of these individuals were obese, doubling the worldwide prevalence of obesity since 1980 (Global Database on Body Mass Index, 2017). Recent projections are that global obesity prevalence will reach $18 \%$ in men and surpass $21 \%$ in women by 2025; severe obesity will exceed $6 \%$ in men and $9 \%$ in women (NCD Risk Factor Collaboration, 2016). Finally, overweight and obesity, estimated with body mass index (BMI, calculated as weight in kilograms divided by height in meters squared), have been associated with decreased functional ability and health status and increased risk of chronic conditions in classical observational studies (Guh, 2009; Fontaine, 2003; Prospective Studies Collaboration, 2009; Stenholm, 2016) and in Mendelian randomization studies (Carreras-Torres, 2017; Carreras-Torres, 2017; Holmes, 2014; Thrift, 2015). Although BMI is well established as a risk factor or indicator, the direct effect of above-normal BMI on health outcomes remains controversial (Gao C. Int J Epidemiol. 2016; Mandviwala T. Curr Atheroscler Rep. 2016). This effect could be secondary, through an influence on the development and severity of cardiovascular risk factors (CRF) such as hypertension, diabetes, and hypercholesterolemia (Bogers, 2007; Global Burden of Metabolic Risk Factors for Chronic Diseases Collaboration, 2014; Jerant, 2012; Poirier P. Circulation. 2006). However, it may also occur in the absence of CRF and may be due to structural and functional changes in excess adipose tissue deposition or to underlying mechanisms that remain unknown (Global Burden of 
Metabolic Risk Factors for Chronic Diseases Collaboration, 2014; Mandviwala T. Curr Atheroscler Rep. 2016; Gao C. Int J Epidemiol. 2016). Teasing apart the effect on health outcomes of above-normal BMI from other comorbidities requires a populationbased cohort with an appropriate sample size, long follow-up, and an exhaustive register of outcomes. Obtaining this information is essential to design effective preventive measures.

The objectives of the present study are: (1) to ascertain the association of BMI and different BMI cut-off points with 10-year cardiovascular disease (CVD) incidence and with cancer and overall mortality in a population-based cohort of more than 54,000 participants, and (2) to describe the interaction of CRF in the association between above-normal BMI values and the risk of all three outcomes.

\section{Methods}

\subsection{Design and participants}

We conducted a pooled analysis of anonymized individual data from 12 population cohorts in 7 Spanish regions, examined between 1992 and 2005 with similar methods; the methodology of this cohort study has been explained elsewhere (Marrugat, 2014). In summary, all participants in the FRESCO cohorts were randomly selected and included participants without previous symptoms or diagnosis of CVDs, aged 35 to 79 years (Supplementary Table 1). The FRESCO study was approved by the local Ethics Committee of the Parc de Salut Mar (authorization \#: 2009/3391/I). All participants were duly informed and signed a consent form to participate in the component studies. 


\subsection{Measurements}

CRF were measured at baseline using standardized methods based on World Health Organization recommendations (Tunstall-Pedoe, 1994). A precision scale of easy calibration was used for weight measurement with participants in underwear. Height was measured with a standard measuring rod, with participants standing barefoot. BMI was determined as weight divided by squared height $\left(\mathrm{kg} / \mathrm{m}^{2}\right)$. Using a standardized smoking questionnaire, participants were classified as smokers (current or quit $<1$ year) or nonsmokers (quit $\geq 1$ year or never smoked).

Blood was withdrawn after 10-14 hours fasting. Total and high-density lipoprotein (HDL) cholesterol concentrations were measured in serum sample aliquots stored at $-80^{\circ} \mathrm{C}$. The Friedewald formula was used to estimate low-density lipoprotein (LDL) cholesterol whenever triglycerides were $<300 \mathrm{mg} / \mathrm{dl}$. A previous study, in which 9 of the 12 FRESCO cohorts participated, obtained good agreement in the measurement of frozen samples from a random subset of participants, establishing that the study's laboratory measurements can be reliably pooled (Grau, 2011). Blood pressure was determined from the average of 2 separate readings taken at least 5 min apart. Hypertension, diabetes, hypercholesterolemia and type of treatment were self-reported by the participants in all studies. We also considered hypertension whenever an individual presented with systolic or diastolic blood pressure $\geq 140 / 90 \mathrm{mmHg}$, respectively; diabetic those participants in whom glycemia $>125 \mathrm{mg} / \mathrm{dl}$ was observed at the time of baseline examination. In both cases, this condition was assigned regardless of their awareness of such disorders. 


\subsection{End-points}

We defined three end-points for the purpose of our analysis: (1) CVD incidence: fatal or nonfatal myocardial infarction or stroke and angina pectoris; (2) Cancer mortality and (3) Overall mortality. Multiple sources were used to identify potential CVD cases, including self-report, re-examination, and linkages to primary care registers, hospital admissions, and regional and national mortality data. All nonfatal diagnoses were verified by examining the corresponding electronic medical record. Unstable angina during follow-up was diagnosed by the presence of angina symptoms without an abnormal increase in the cardiac enzymes or troponin and with relevant changes in serial electrocardiograms. Alternatively, with or without electrocardiographic changes, a diagnosis was made when suggestive symptoms were recorded during the event and confirmed either by a positive coronary angiography (stenosis $>70 \%$ ) or by a positive stress test with or without isotopic stress gammagraphy (Marrugat, 2014).

Vital status and causes of death during 10-year follow-up were ascertained by reviewing medical records and by linkage with the official death registry, coded according to the $10^{\text {th }}$ revision of the International Classification of Diseases (ICD). Mortality was classified as due to CVD (ICD F01, I20-I25, I60-I69, G45), and all malignant neoplasms (ICD C00-C99, D1-D48) (Baena-Diez, 2016).

\subsection{Statistical analysis}

Three BMI categories were defined: (1) normal weight, BMI $\geq 18.5$ and $<25 \mathrm{~kg} / \mathrm{m}^{2}$; (2) overweight, BMI $\geq 25$ and $<30 \mathrm{~kg} / \mathrm{m}^{2}$; and (3) obesity, BMI $\geq 30 \mathrm{~kg} / \mathrm{m}^{2}$. 
Variables were summarized as mean and standard deviation (SD) and median and interquartile range (IQR) when the distribution departed from normal. Categorical variables were described as proportions. Chi-square was computed to test differences for categorical variables at baseline; analysis of variance and Kruskall-Wallis tests were used for variables that did and did not follow a normal distribution, respectively. Tenyear differences in CVD incidence and in cancer and overall mortality by BMI categories at the end of the follow-up were computed by the Kaplan-Meier method. To assess the linear trend of variables by BMI categories, analysis of variance and chisquare tests were used. BMI categories and CRF were also summarized by outcome.

We tested the linearity of the association between continuous BMI and the risk of all three end-points considered. Adjusted Cox regression models were fitted whenever the result did not reveal a nonlinear component of the relationship.

Effect modification of the relationship between sex, CRF (age, diabetes, hypertension, smoking, total and HDL cholesterol) and BMI categories and each endpoint was tested with the -2 log-likelihood test of nested models with and without interaction terms. Two multivariable sex-stratified models were fitted for each endpoint. The first was adjusted for age and the second was further adjusted for diabetes, hypertension, smoking, total and HDL cholesterol and for the significant interactions between the CRFs and BMI category.

Sensitivity analysis was conducted using standard BMI categories: (1) normal weight, BMI $\geq 18.5$ and $<27 \mathrm{~kg} / \mathrm{m} 2$, or BMI $\geq 25$ and $<27 \mathrm{~kg} / \mathrm{m}^{2}$ with no further CRF; (2) overweight, $\mathrm{BMI} \geq 25$ and $<27 \mathrm{~kg} / \mathrm{m}^{2}$ with at least one additional $\mathrm{CRF}$, or $\mathrm{BMI} \geq 27$ and $<30 \mathrm{~kg} / \mathrm{m}^{2}$; and (3) obesity, BMI $\geq 30 \mathrm{~kg} / \mathrm{m}^{2}$. Additionally, we conducted a competing risk analysis (Fine \& Gray regression) considering death due to CVD and 
cancer. Finally, we reanalyzed the data after excluding angina from the definition of fatal and non-fatal CVD.

All calculations were made with R statistical package (R Foundation for Statistical Computing, Vienna, Austria; version 3.3.2).

\section{Results}

The FRESCO cohort included 54,446 individuals with valid BMI measurements, of which $46.5 \%$ presented with overweight and $27.8 \%$ with obesity. Figure 1 shows the end-point distribution in all three BMI categories over the 10-year median follow-up (interquartile range 8.8-10).

\subsection{Cardiovascular risk profile according to BMI categories and to end-points}

Individuals with overweight or obesity were significantly older, less likely to smoke, and had higher systolic and diastolic blood pressure and total and LDL cholesterol, triglycerides and glycemia values, compared with normal-weight individuals, and more often presented with hypertension and diabetes. In the highest BMI categories, significantly higher crude rates of 10-year fatal and nonfatal CVD incidence, cancer mortality, and overall mortality were observed in women, but only CVD in men (Table 1).

Individuals who presented with an outcome in the follow-up were, in general, older, less likely to smoke, and had higher systolic and glycemia values, compared with those who do not present, and more often presented with hypertension and diabetes (Supplementary Table 2). 


\subsection{Risk of adverse health outcomes by BMI values}

The age-adjusted association between BMI, as a continuous variable, and the risk of all three end-points showed a significant linear increasing trend for CVD incidence in both sexes. On the contrary, BMI significantly decreased the risk of cancer death and showed a U-shaped curve for overall mortality in men (Fig. 2).

An analysis by BMI categories suggested the CRF that had a modification effect for all three end-points. Multivariable models were adjusted for these interactions.

\subsection{Risk of cardiovascular disease and death, by BMI category}

We found a significant effect modification of the relationship between sex, CRF (age, diabetes, hypertension, smoking, and total and HDL cholesterol), BMI categories, and each end-point in almost all -2 log-likelihood tests of nested models. After adjustment for potential confounders and for the interaction with age by categories of BMI, CVD-related risk was significantly higher in women with overweight or obesity, compared to normal weight [Hazard ratio=2.34 (95\% confidence interval: 1.19-4.61) and 5.65 (1.54-20.73), respectively]. When the model was adjusted for the interaction with diabetes, by categories of BMI, the result was not significant in men. In women, overweight and obesity significantly increased the risk of cancer death after adjustment for the interaction with total cholesterol, by categories of BMI [3.98 (1.53-10.37) and 11.61 (1.93-69.72), respectively]. In obese men, the risk of cancer death was also significantly increased, but with lower magnitude than in women with obesity [1.62 $(1.03-2.54)]$. In this case, the model was further adjusted for the interaction with hypertension, by the categories of BMI. 
After adjustment for the interaction with hypertension, a significant linear association was observed between overall mortality risk and BMI category in men; in women, the adjusted hazard ratio was marginally significant [1.35 (0.96-1.89)] (Tables 3 and 4). Figure 3 describes the effect of the significant interactions on every outcome considered.

\subsection{Sensitivity analysis}

All sensitivity analyses yielded results similar to the primary analysis. On the one hand, Supplementary Tables 3-6 show the cardiovascular risk profile and the adverse health outcomes distribution according to a second BMI stratification, which considers the prevalence of CRF. Supplementary Table 7 shows the competing risks (Fine \& Gray regression) of cause-specific deaths (CVD and cancer). Finally, the sensitivity analysis using a CVD end-point excluding angina is shown in Supplementary Table 8.

\section{Discussion}

Above-normal BMI has been associated with disability and premature mortality. In the present study, obesity increased the risk of fatal and non-fatal CVD events, cancer death, and overall mortality. Aging, hypertension, hypercholesterolemia, and diabetes may have a role as effect modifiers in these relationships, although the effect was confusing in individuals with those CRF. In individuals with no effect modification, above-normal BMI may act as an independent risk factor that follows a dose-response pattern, suggesting that there is no healthy pattern of increased weight (Kramer, 2013; Borrell, 2014). This observation may reflect, to some extent, the role of obesity as an 
effect mediator between CRF and the development of adverse health outcomes (i.e., serving as a risk marker) (Mandviwala, 2016).

\subsection{BMI as a risk factor for cardiovascular disease}

In the age-adjusted analysis, BMI presents a clear relationship with fatal and nonfatal CVD. The role of obesity as an independent risk factor or a risk marker has long been discussed (Mandviwala, 2016). Obesity increases the risk of coronary artery disease (the most incident CVD event) secondarily through its influence on the development and severity of comorbidities such as diabetes, hypertension, or dyslipidemia, acting in these cases as a risk marker (Poirier, 2006). Inclusion of aging as an effect modifier showed that overweight and obesity in women were independent risk factors for fatal and non-fatal CVD. This analysis underlines the behavior of abovenormal BMI levels as an independent risk factor, in the absence of other effect modifiers.

The Global Burden of Metabolic Risk Factors for Chronic Diseases Collaboration study found that the association between adiposity and CVD was not completely explained by the three mediators studied (blood pressure, cholesterol, and glucose). The unexplained risk might be caused by other pathways, such as endothelial dysfunction, increase in thrombogenic factors, and the remaining effect of increased sympathetic activity and systemic inflammation not related to risk factors, which might be more important in individuals with obesity, compared to overweight (Global Burden of Metabolic Risk Factors for Chronic Diseases Collaboration, 2014). This significant effect was previously observed in young populations with coronary artery disease, which traditionally have had a greater prevalence of obesity (Choudhury, 1999). In the 
CRUSADE registry, obesity was the strongest risk factor linked to non-ST elevation myocardial infarction events, followed by tobacco use (Madala, 2008). Long-term exposure to above-normal BMI leads to the development of CRF that may exceed the effect size of classical risk factors alone in calculating the risk of cardiovascular events (Yan, 2006; Twig, 2016).

\subsection{Overweight, obesity, and mortality}

We observed a U-shaped curve for the association between BMI values and overall mortality risk, particularly in men. This was the only outcome in which a linear trend was not observed. This characteristic shape has also been observed in the association between BMI values and CVD and overall mortality across different regions in the world (Chen, 2013; Berrington de Gonzalez, 2010; Global BMI Mortality Collaboration, 2010; Ponce-Garcia, 2015; Padwal, 2016; Yi, 2015). Previous analysis shows that clustering CRF (diabetes, hypertension, smoking, dyslipidemia) with obesity in statistical analysis may attenuate the effect size of the latter on health outcomes (Jerant, 2012). The mortality risk in individuals with overweight has been discussed with quite divergent results (Chen, 2013; Berrington de Gonzalez, 2010; Global BMI Mortality Collaboration, 2010; Ponce-Garcia, 2015; Padwal, 2016; Yi, 2015; Orpana, 2010).

Concurring with previous studies (Reeves, 2007; Renehan, 2010), cancer mortality risk increased dramatically in women with overweight and obesity, particularly in those with total cholesterol $<220 \mathrm{mg} / \mathrm{dl}$. These results underline the sex-related differences in the role of above-normal BMI, with the effect of obesity being particularly malignant in women. 


\subsection{Characteristics and limitations}

The FRESCO project is a pooled analysis of 12 population-based cohorts of individuals aged 35 to 79 years with two major strengths: the population representativeness and the comparativeness between all component studies that followed the MONICA standard guidelines to collect data (Tunstall-Pedoe, 1994). However, our study has several limitations. First, we used a single BMI measurement at baseline and did not consider any further measurements during the 10-year follow-up to monitor changes over time. Second, we did not consider other measures of obesity (e.g., abdominal circumference, waist-to-hip ratio); however, past collaborative studies including cohorts from all over the world have shown that BMI is in itself a strong predictor of overall mortality (Prospective Studies Collaboration, 2009; Global BMI Mortality Collaboration, 2010). Third, some variables with a potential effect on the BMI values and on the outcomes (e.g., social status, deprivation, alcohol use, physical activity, diet) were not collected in the FRESCO Project. Residual confounding is likely to exist in our analysis despite all our efforts. Additionally, the heterogeneity between the component cohorts in transient ischemic attack events, likely due to the difficulty of identifying the disorder, prevented its inclusion as an outcome of this analysis. Fourth, survival bias is inherent to cohort studies, and is likely to apply to the present analysis, especially among people recruited at older ages. This bias may hamper the validity of some of the associations observed, particularly in men because their life expectancy is lower than in women (INE, 2017). Finally, past studies have shown that changes in obesity and BMI take some time to affect incidence and mortality rates at a population level. For instance, in the context of the Framingham Heart Study, obesity was associated with increased relative risk for development of coronary artery disease in a 
population, ages 35 to 75, over a 44-year follow-up (Wilson, 2002). In addition, a metaanalysis has found that studies with more than 10 years of follow-up were more likely to observe a significant association between obesity and coronary artery disease (Bogers, 2007). Nonetheless, our analysis, with a 10-year median follow-up, showed significantly higher mortality rates for all endpoints considered in individuals exposed to above normal BMI values, and particularly obesity. The use of Mendelian randomization methodology, in theory being less affected by bias or confounding, has the potential to establish a causal relationship between modifiable exposures and disease outcomes, compared to observational (non-genetic studies). This approach could help in understanding the complexity in the link between different grades of BMI and the endpoints analyzed.

\section{Conclusion}

Overweight and obesity significantly increased the risk of cancer death and of fatal and non-fatal cardiovascular disease in women; whereas obese men presented a significant higher risk of death from all causes and for cancer, specifically. Aging, diabetes, hypertension, and total cholesterol may act as effect modifiers in these associations.

\section{Conflict of interest}

None to declare. 


\section{Acknowledgements}

This analysis of the FRESCO data was financed with an unconditional grant from Novo Nordisk. The work of data merging was supported by MARATO TV3 (081630), Instituto de Salud Carlos III — Fondo Europeo de Desarrollo Regional — European Regions Development Funds [Red de Investigación Cardiovascular RD12/0042 (Programa HERACLES); Red RedIAPP RD12/0005; RD06/0018; PI081327; PI1101801]; AGAUR [2014 SGR 240]; MG was supported by the Instituto de Salud Carlos III — Fondo Europeo de Desarrollo Regional — European Regions Development Fund FEDER (FEDER [FIS CP12/03287]).

The authors wish to thank Ruth Martí, Susana Tello, Marta Cabañero, Yolanda Ferrer, Sandra Farré, and Esmeralda Gómez, IMIM- Hospital del Mar Research Institute, Barcelona (Spain), for data management and administrative support, and Elaine Lilly, Ph.D., for English language revision of the manuscript. We also appreciate the collaboration of the Registre de Mortalitat de Catalunya del Servei d'Informació i Estudis, Departament de Salut, Generalitat de Catalunya (Anna Puigdefàbregas, Gloria Ribas, and Rosa Gispert).

\section{References}

Baena-Díez, J.M., Peñafiel, J., Subirana, I., Ramos, R., Elosua, R., Marín-Ibañez, A., et al., 2016. Risk of Cause-Specific Death in Individuals With Diabetes: A Competing Risks Analysis. Diabetes Care. 39 (11), 1987-1995.

Berrington de Gonzalez, A., Hartge, P., Cerhan, J.R., Flint, A.J., Hannan, L., MacInnis, R.J., et al., 2010. Body-mass index and mortality among 1.46 million white adults. N. Engl. J. Med. 363 (23), 2211-9. 
Bogers, R.P., Bemelmans, W.J., Hoogenveen, R.T., Boshuizen, H.C., Woodward, M., Knekt, P., et al., 2007. Association of overweight with increased risk of coronary heart disease partly independent of blood pressure and cholesterol levels: a metaanalysis of 21 cohort studies including more than 300000 persons. Arch. Intern. Med. 167 (16), 1720-8.

Borrell, L.N., Samuel, L., 2014. Body mass index categories and mortality risk in US adults: the effect of overweight and obesity on advancing death. Am. J. Public Health 104 (3), 512-9.

Carreras-Torres, R., Johansson, M., Haycock, P.C., Wade, K.H., Relton, C.L., Martin, R.M., et al., 2017. Obesity, metabolic factors and risk of different histological types of lung cancer: A Mendelian randomization study. PLoS One 12 (6), e0177875.

Carreras-Torres, R., Johansson, M., Gaborieau, V., Haycock, P.C., Wade, K.H., Relton, C.L., et al., 2017. The Role of Obesity, Type 2 Diabetes, and Metabolic Factors in Pancreatic Cancer: A Mendelian Randomization Study. J. Natl. Cancer. Inst. 109(9).

Chen, Y., Copeland, W.K., Vedanthan, R., Grant, E., Lee, J.E., Gu, D., et al., 2013. Association between body mass index and cardiovascular disease mortality in east Asians and south Asians: pooled analysis of prospective data from the Asia Cohort Consortium. B.M.J. 347, f5446.

Choudhury, L., Marsh, J.D., 1999. Myocardial infarction in young patients. Am. J. Med. $107(3), 254-61$.

Finucane, M.M., Stevens, G.A., Cowan, M.J., Danaei, G., Lin, J.K., Paciorek, C.J., et al., 2011. National, regional, and global trends in body-mass index since 1980: 
systematic analysis of health examination surveys and epidemiological studies with 960 country-years and 9·1 million participants. Lancet 377 (9765), 557-67. Flegal, K.M., Kit, B.K., Orpana, H., Graubard, B.I., 2013. Association of all-cause mortality with overweight and obesity using standard body mass index categories: a systematic review and meta-analysis. JAMA 309 (1), 71-82.

Fontaine, K.R., Redden, D.T., Wang, C., Westfall, A.O., Allison, D.B., 2003. Years of life lost due to obesity. JAMA 289 (2), 187-93.

Gao, C., Patel, C.J., Michailidou, K., Peters, U., Gong, J., Schildkraut, J., et al., 2016. Mendelian randomization study of adiposity-related traits and risk of breast, ovarian, prostate, lung and colorectal cancer. Int. J. Epidemiol. 45(3), 896-908.

GBD 2015 Obesity Collaborators, 2017. Health Effects of Overweight and Obesity in 195 Countries over 25 Years. N. Engl. J. Med 377 (1), 13-27.

Global BMI Mortality Collaboration., 2016. Body-mass index and all-cause mortality: individual-participant-data meta-analysis of 239 prospective studies in four continents. Lancet 388 (10046), 776-86.

Global Burden of Metabolic Risk Factors for Chronic Diseases Collaboration (BMI Mediated Effects)., 2014. Metabolic mediators of the effects of body-mass index, overweight, and obesity on coronary heart disease and stroke: a pooled analysis of 97 prospective cohorts with 1·8 million participants. Lancet 383(9921):970-83.

Global Database on Body Mass Index. World Health Organization. Accessed at: who.int/mediacentre/factsheets/fs311/en on 17 January 2017.

Grau, M., Elosua, R., Cabrera de León, A., Guembe, M.J., Baena-Díez, J.M., Vega Alonso, T., et al., 2011. Cardiovascular risk factors in Spain in the first decade of 
the 21 st Century, a pooled analysis with individual data from 11 population-based studies: the DARIOS study. Rev. Esp. Cardiol. 64 (4), 295-304.

Guh, D.P., Zhang, W., Bansback, N., Amarsi, Z., Birmingham, C.L., Anis, A.H., 2009. The incidence of co-morbidities related to obesity and overweight: a systematic review and meta-analysis. BMC Public Health 9, 88.

Holmes, M.V., Lange, L.A., Palmer, T., Lanktree, M.B., North, K.E., Almoguera, B., et al., 2014. Causal effects of body mass index on cardiometabolic traits and events: a Mendelian randomization analysis. Am. J. Hum. Genet. 94 (2), 198-208.

National Statistics Institute (Spain). INEbase [on line]. [Madrid]: Available at: www.ine.es

Jerant, A., Franks, P., 2012. Body mass index, diabetes, hypertension, and short-term mortality: a population-based observational study, 2000-2006. J. Am. Board. Fam. Med. 25 (4), 422-31.

Kramer, C.K., Zinman, B., Retnakaran, R., 2013. Are metabolically healthy overweight and obesity benign conditions?: A systematic review and meta-analysis. Ann Intern Med 159 (11), 758-69.

Madala, M.C., Franklin, B.A., Chen, A.Y., Berman, A.D., Roe, M.T., Peterson, E.D., et al., 2008. Obesity and age of first non-ST-segment elevation myocardial infarction. J. Am. Coll. Cardiol. 52 (12), 979-85.

Mandviwala, T., Khalid, U., Deswal, A., 2016. Obesity and Cardiovascular Disease: a Risk Factor or a Risk Marker? Curr. Atheroscler. Rep. 18 (5), 21.

Marrugat, J., Subirana, I., Ramos, R., Vila, J., Marín-Ibañez, A., Guembe, M.J., et al., 2014. Derivation and validation of a set of 10-year cardiovascular risk predictive functions in Spain: the FRESCO Study. Prev. Med. 61, 66-74. 
NCD Risk Factor Collaboration (NCD-RisC), 2016. Trends in adult body-mass index in 200 countries from 1975 to 2014: a pooled analysis of 1698 population-based measurement studies with $19 \cdot 2$ million participants. Lancet 387 (10026), 13771396.

Orpana, H.M., Berthelot, J.M., Kaplan, M.S., Feeny, D.H., McFarland, B., Ross, N.A., 2010. BMI and mortality: results from a national longitudinal study of Canadian adults. Obesity (Silver Spring) 18 (1), 214-8.

Padwal, R., Leslie, W.D., Lix, L.M., Majumdar, S.R., 2016. Relationship Among Body Fat Percentage, Body Mass Index, and All-Cause Mortality: A Cohort Study. Ann. Intern. Med., 164 (8), 532-41.

Poirier, P., Giles, T.D., Bray, G.A., Hong, Y., Stern, J.S., Pi-Sunyer, F.X., 2006. Obesity and cardiovascular disease: pathophysiology, evaluation, and effect of weight loss: an update of the 1997 American Heart Association Scientific Statement on Obesity and Heart Disease from the Obesity Committee of the Council on Nutrition, Physical Activity, and Metabolism. Circulation 113 (6), 898-918.

Ponce-Garcia, I., Simarro-Rueda, M., Carbayo-Herencia, J.A., Divisón-Garrote, J.A., Artigao-Ródenas, L.M., Botella-Romero, F., et al., 2015. Prognostic value of obesity on both overall mortality and cardiovascular disease in the general population. PLoS One. 10 (5), e0127369.

Prospective Studies Collaboration, 2009. Body-mass index and cause-specific mortality in 900000 adults: collaborative analyses of 57 prospective studies. Lancet 373 (9669), 1083-96. 
Reeves, G.K., Pirie, K., Beral, V., Green, J., Spencer, E., Bull, D.; Million Women Study Collaboration., 2007. Cancer incidence and mortality in relation to body mass index in the Million Women Study: cohort study. B.M.J. 335 (7630), 1134.

Renehan, A.G., Soerjomataram, I., Tyson, M., Egger, M., Zwahlen, M., Coebergh, J.W., et al., 2010. Incident cancer burden attributable to excess body mass index in 30 European countries. Int. J. Cancer. 126 (3), 692-702.

Stenholm, S., Head, J., Kivimäki, M., Kawachi, I., Aalto, V., Zins, M., et al., 2016. Smoking, physical inactivity and obesity as predictors of healthy and disease-free life expectancy between ages 50 and 75: a multicohort study. Int. J. Epidemiol. 45 (4), 1260-1270.

Thrift, A.P., Gong, J., Peters, U., Chang-Claude, J., Rudolph, A., Slattery, M.L., et al., 2015. Mendelian Randomization Study of Body Mass Index and Colorectal Cancer Risk. Cancer Epidemiol. Biomarkers Prev. 24(7), 1024-31.

Tunstall-Pedoe, H., Kuulasmaa, K., Amouyel, P., Arveiler, D., Rajakangas, A.M., Pajak, A., 1994. Myocardial infarction and coronary deaths in the World Health Organization MONICA Project. Registration procedures, event rates, and casefatality rates in 38 populations from 21 countries in four continents. Circulation $90(1), 583-612$.

Twig, G., Yaniv, G., Levine, H., Leiba, A., Goldberger, N., Derazne, E., et al., 2016. Body-Mass Index in 2.3 Million Adolescents and Cardiovascular Death in Adulthood. N Engl J Med. 374 (25), 2430-40.

Wilson, P.W., D'Agostino, R.B., Sullivan, L., Parise, H., Kannel, W.B., 2002. Overweight and obesity as determinants of cardiovascular risk: the Framingham experience. Arch Intern Med. 162(16), 1867-72.Yan, L.L., Daviglus, M.L., Liu, 
K., Stamler, J., Wang, R., Pirzada, A., et al., 2006. Midlife body mass index and hospitalization and mortality in older age. JAMA 295(2), 190-8.

Yi, S.W., Ohrr, H., Shin, S.A., Yi, J.J., 2015. Sex-age-specific association of body mass index with all-cause mortality among 12.8 million Korean adults: a prospective cohort study. Int. J. Epidemiol .44 (5), 1696-705. 


\section{FIGURE LEGENDS}

Figure 1. Flow chart of the participants in the FRESCO Study (Spain).

Figure 2. Age-adjusted risk of 10-year fatal and nonfatal cardiovascular disease

incidence $(\mathrm{A})$, cancer death $(\mathrm{B})$, and overall mortality $(\mathrm{C})$ by body mass index, stratified by sex in the FRESCO Study (Spain).

Figure 3. Adjusted risk of 10-year fatal and nonfatal cardiovascular disease incidence (A), cancer death (B), and overall mortality (C), stratified by sex in the FRESCO Study (Spain).

Models were adjusted for the cardiovascular risk factor included in the legend by categories of body mass index. Filled-in dots indicate $\mathrm{p}<0.005$ 
Table 1. Baseline characteristics and outcomes of the participants in the FRESCO Study by sex by body mass index categories

\begin{tabular}{|c|c|c|c|c|c|c|c|c|}
\hline & \multicolumn{4}{|c|}{ Men } & \multicolumn{4}{|c|}{ Women } \\
\hline & \multicolumn{3}{|c|}{ Body mass index } & \multicolumn{5}{|c|}{ Body mass index } \\
\hline & $\begin{array}{c}\geq 18.5 \&<25 \\
\mathrm{~N}=5448\end{array}$ & $\begin{array}{c}\geq 25 \&<30 \\
N=13546\end{array}$ & $\begin{array}{c}\geq 30 \\
\mathrm{~N}=6118\end{array}$ & $\begin{array}{l}p \text { for } \\
\text { trend }\end{array}$ & $\begin{array}{c}\geq 18.5 \&<25 \\
N=8497\end{array}$ & $\begin{array}{c}\geq 25 \&<30 \\
N=11783\end{array}$ & $\begin{array}{c}\geq 30 \\
\mathrm{~N}=9040\end{array}$ & $\begin{array}{l}p \text { for } \\
\text { trend }\end{array}$ \\
\hline Age, mean (SD) & $54(12)$ & $56(12)$ & $56(11)$ & $<0.001$ & $51(12)$ & $57(12)$ & $59(11)$ & $<0.001$ \\
\hline Smoker, n (\%) & $2074(38.3)$ & $3725(27.6)$ & $1745(28.8)$ & $<0.001$ & $1941(23.0)$ & $1235(10.6)$ & $602(6.7)$ & $<0.001$ \\
\hline Systolic BP, mean (SD) & $131(18)$ & $137(18)$ & $142(19)$ & $<0.001$ & $124(20)$ & $134(20)$ & $141(20)$ & $<0.001$ \\
\hline Diastolic BP, mean (SD) & $78(9)$ & $81(9)$ & $83(10)$ & $<0.001$ & $75(9)$ & $79(9)$ & $82(9)$ & $<0.001$ \\
\hline Hypertension, n (\%) & $2139(41.6)$ & $7563(58.3)$ & $4272(72.6)$ & $<0.001$ & $2449(30.6)$ & $6093(54.2)$ & $6104(70.7)$ & $<0.001$ \\
\hline Total cholesterol, mean (SD) & $215(40)$ & $222(40)$ & $222(41)$ & $<0.001$ & $217(41)$ & $228(42)$ & $227(41)$ & $<0.001$ \\
\hline HDL cholesterol, mean (SD) & $53(14)$ & $49(12)$ & $47(12)$ & $<0.001$ & $63(15)$ & $58(14)$ & $54(13)$ & $<0.001$ \\
\hline LDL cholesterol, mean (SD) & $142(38)$ & $149(38)$ & $149(38)$ & $<0.001$ & $138(39)$ & $150(40)$ & $150(39)$ & $<0.001$ \\
\hline Triglycerides, median [IQR] & 90 [70-122] & $106[79-146]$ & 119 [88-166] & $<0.001$ & 74 [58-97] & $91[69-122]$ & 108 [81-146] & $<0.001$ \\
\hline Glycemia, median [IQR] & 94 [86-103] & 98 [89-110] & 102 [92-119] & $<0.001$ & 88 [82-95] & 92 [85-101] & 97 [88-112] & $<0.001$ \\
\hline Diabetes, n (\%) & $679(12.6)$ & $2332(17.4)$ & $1540(25.3)$ & $<0.001$ & $531(6.3)$ & $1474(12.6)$ & $1983(22.2)$ & $<0.001$ \\
\hline Fatal and non fatal & $254(6.2)$ & $731(7.0)$ & $417(8.5)$ & $<0.001$ & $152(2.3)$ & $360(3.8)$ & $328(4.6)$ & $<0.001$ \\
\hline \multicolumn{9}{|l|}{ cardiovascular disease*, $\mathrm{n}(\%)$} \\
\hline Cancer death*, n (\%) & $124(2.4)$ & $283(2.2)$ & $129(2.3)$ & 0.523 & $60(0.8)$ & $139(1.2)$ & $111(1.3)$ & 0.001 \\
\hline Overall mortality*, n (\%) & $359(6.9)$ & $740(5.8)$ & $401(6.9)$ & 0.979 & 207 (2.6) & $404(3.6)$ & $352(4.0)$ & $<0.001$ \\
\hline
\end{tabular}

Abbreviations: BP, Blood pressure; CRF, Cardiovascular risk factors; CVD, Cardiovascular disease; IQR, Interquartile range; HDL, High-density lipoprotein; LDL, Low-density lipoprotein; SD, Standard deviation. *Computed with Kaplan-Meier method 
Table 2. Hazard ratios for fatal and non-fatal cardiovascular disease, cancer death, and overall mortality among men with overweight or obesity, compared to normal weight, at baseline, estimated by Cox regression, after adjustment for potential risk factors and significant interactions.

\begin{tabular}{|c|c|c|c|c|c|c|}
\hline & \multicolumn{2}{|c|}{$\begin{array}{c}\text { Fatal and non-fatal cardiovascular } \\
\text { disease }\end{array}$} & \multicolumn{2}{|c|}{ Cancer death } & \multicolumn{2}{|c|}{ Overall death } \\
\hline & Model 1 & Model 2 & Model 1 & Model 2 & Model 1 & Model 2 \\
\hline & $\begin{array}{c}\text { HR } \\
(95 \% \mathrm{CI})\end{array}$ & $\begin{array}{c}\text { HR } \\
(95 \% \mathrm{CI})\end{array}$ & $\begin{array}{c}\text { HR } \\
(95 \% \mathrm{CI})\end{array}$ & $\begin{array}{c}\text { HR } \\
(95 \% \mathrm{CI})\end{array}$ & $\begin{array}{c}\text { HR } \\
(95 \% \mathrm{CI})\end{array}$ & $\begin{array}{c}\text { HR } \\
(95 \% \mathrm{CI})\end{array}$ \\
\hline Overweight & $\begin{array}{c}1.02 \\
(0.88-1.17)\end{array}$ & $\begin{array}{c}0.94 \\
(0.80-1.10)\end{array}$ & $\begin{array}{c}0.80 \\
(0.65-0.99)\end{array}$ & $\begin{array}{c}1.08 \\
(0.81-1.44)\end{array}$ & $\begin{array}{c}0.72 \\
(0.64-0.82)\end{array}$ & $\begin{array}{c}0.86 \\
(0.73-1.03)\end{array}$ \\
\hline Obesity & $\begin{array}{c}1.30 \\
(1.11-1.52)\end{array}$ & $\begin{array}{c}1.15 \\
(0.94-1.41)\end{array}$ & $\begin{array}{c}0.83 \\
(0.65-1.06)\end{array}$ & $\begin{array}{c}1.62 \\
(1.03-2.54)\end{array}$ & $\begin{array}{c}0.89 \\
(0.77-1.02)\end{array}$ & $\begin{array}{c}1.34 \\
(1.01-1.76)\end{array}$ \\
\hline Age & $\begin{array}{c}1.05 \\
(1.04-1.06)\end{array}$ & $\begin{array}{c}1.05 \\
(1.04-1.06)\end{array}$ & $\begin{array}{c}1.07 \\
(1.06-1.08)\end{array}$ & $\begin{array}{c}1.07 \\
(1.06-1.08)\end{array}$ & $\begin{array}{c}1.08 \\
(1.08-1.09)\end{array}$ & $\begin{array}{c}1.08 \\
(1.08-1.09)\end{array}$ \\
\hline Diabetes & -- & $\begin{array}{c}2.16 \\
(1.72-2.71)\end{array}$ & -- & $\begin{array}{c}1.39 \\
(1.14-1.71)\end{array}$ & -- & $\begin{array}{c}1.55 \\
(1.38-1.75)\end{array}$ \\
\hline Smoking & -- & $\begin{array}{c}1.50 \\
(1.33-1.70)\end{array}$ & -- & $\begin{array}{c}1.22 \\
(0.99-1.50)\end{array}$ & -- & $\begin{array}{c}1.33 \\
(1.17-1.51)\end{array}$ \\
\hline Hypertension & -- & $\begin{array}{c}1.62 \\
(1.40-1.87)\end{array}$ & -- & $\begin{array}{c}1.40 \\
(1.00-1.96)\end{array}$ & -- & $\begin{array}{c}1.32 \\
(1.07-1.62)\end{array}$ \\
\hline Total cholesterol & -- & $\begin{array}{c}1.04 \\
(1.03-1.05)\end{array}$ & -- & $\begin{array}{c}0.97 \\
(0.95-1.00)\end{array}$ & -- & $\begin{array}{c}0.98 \\
(0.97-1.00)\end{array}$ \\
\hline HDL cholesterol & -- & $\begin{array}{c}0.85 \\
(0.80-0.89)\end{array}$ & -- & $\begin{array}{c}1.02 \\
(0.95-1.10)\end{array}$ & -- & $\begin{array}{c}0.98 \\
(0.94-1.02)\end{array}$ \\
\hline $\begin{array}{l}\text { Diabetes by } \\
\text { categories of BMI }\end{array}$ & -- & $\begin{array}{c}0.75 \\
(0.63-0.89)\end{array}$ & -- & -- & -- & -- \\
\hline $\begin{array}{l}\text { Hypertension by } \\
\text { categories of BMI }\end{array}$ & -- & -- & -- & $\begin{array}{c}0.61 \\
(0.47-0.80)\end{array}$ & -- & $\begin{array}{c}0.72 \\
(0.61-0.85)\end{array}$ \\
\hline
\end{tabular}

Models were mutually adjusted

CI, Confidence interval; HR, Hazard ratio 
Table 3. Hazard ratios for fatal and non-fatal cardiovascular disease, cancer death, and overall mortality among men with overweight or obesity, compared to normal weight at baseline, estimated by Cox regression, after adjustment for potential risk factors and significant interactions.

\begin{tabular}{|c|c|c|c|c|c|c|}
\hline & \multicolumn{2}{|c|}{$\begin{array}{l}\text { Fatal and non-fatal } \\
\text { cardiovascular disease }\end{array}$} & \multicolumn{2}{|c|}{ Cancer death } & \multicolumn{2}{|c|}{ Overall death } \\
\hline & Model 1 & Model 2 & Model 1 & Model 2 & Model 1 & Model 2 \\
\hline & $\begin{array}{c}\text { HR } \\
(95 \% \mathrm{CI})\end{array}$ & $\begin{array}{c}\text { HR } \\
(95 \% \mathrm{CI})\end{array}$ & $\begin{array}{c}\text { HR } \\
(95 \% \mathrm{CI})\end{array}$ & $\begin{array}{c}\text { HR } \\
(95 \% \mathrm{CI})\end{array}$ & $\begin{array}{c}\text { HR } \\
(95 \% \mathrm{CI})\end{array}$ & $\begin{array}{c}\text { HR } \\
(95 \% \mathrm{CI})\end{array}$ \\
\hline Overweight & $\begin{array}{c}1.19 \\
(0.98-1.44)\end{array}$ & $\begin{array}{c}2.34 \\
(1.19-4.61)\end{array}$ & $\begin{array}{c}1.27 \\
(0.93-1.72)\end{array}$ & $\begin{array}{c}3.98 \\
(1.53-10.37)\end{array}$ & $\begin{array}{c}0.98 \\
(0.83-1.16)\end{array}$ & $\begin{array}{c}1.10 \\
(0.89-1.36)\end{array}$ \\
\hline Obesity & $\begin{array}{c}1.37 \\
(1.13-1.66)\end{array}$ & $\begin{array}{c}5.65 \\
(1.54-20.73)\end{array}$ & $\begin{array}{c}1.26 \\
(0.92-1.73)\end{array}$ & $\begin{array}{c}11.61 \\
(1.93-69.72)\end{array}$ & $\begin{array}{c}1.05 \\
(0.89-1.25)\end{array}$ & $\begin{array}{c}1.28 \\
(0.92-1.79)\end{array}$ \\
\hline Age & $\begin{array}{c}1.08 \\
(1.07-1.08)\end{array}$ & $\begin{array}{c}1.08 \\
(1.07-1.10)\end{array}$ & $\begin{array}{c}1.06 \\
(1.05-1.07)\end{array}$ & $\begin{array}{c}1.06 \\
(1.05-1.07)\end{array}$ & $\begin{array}{c}1.09 \\
(1.09-1.10)\end{array}$ & $\begin{array}{c}1.09 \\
(1.09-1.10)\end{array}$ \\
\hline Diabetes & -- & $\begin{array}{c}1.87 \\
(1.59-2.18)\end{array}$ & -- & $\begin{array}{c}1.76 \\
(1.34-2.32)\end{array}$ & -- & $\begin{array}{c}1.81 \\
(1.55-2.10)\end{array}$ \\
\hline Smoking & -- & $\begin{array}{c}2.06 \\
(1.53-2.76)\end{array}$ & -- & $\begin{array}{c}0.89 \\
(0.52-1.51)\end{array}$ & -- & $\begin{array}{c}0.94 \\
(0.65-1.35)\end{array}$ \\
\hline Hypertension & -- & $\begin{array}{c}1.99 \\
(1.61-2.47)\end{array}$ & -- & $\begin{array}{c}0.65 \\
(0.49-0.85)\end{array}$ & -- & $\begin{array}{c}0.98 \\
(0.96-1.00)\end{array}$ \\
\hline Total cholesterol & -- & $\begin{array}{c}1.02 \\
(1.00-1.04)\end{array}$ & -- & $\begin{array}{c}1.05 \\
(0.99-1.10)\end{array}$ & -- & $\begin{array}{c}0.91 \\
(0.86-0.96)\end{array}$ \\
\hline HDL cholesterol & -- & $\begin{array}{c}0.86 \\
(0.81-0.91)\end{array}$ & -- & $\begin{array}{c}0.92 \\
(0.84-1.00)\end{array}$ & -- & $\begin{array}{c}0.98 \\
(0.94-1.02)\end{array}$ \\
\hline $\begin{array}{l}\text { Hypertension by categories of } \\
\text { BMI }\end{array}$ & -- & -- & -- & -- & -- & $\begin{array}{c}0.81 \\
(0.66-0.98)\end{array}$ \\
\hline Age by categories of BMI & -- & $\begin{array}{c}0.99 \\
(0.98-1.00)\end{array}$ & -- & -- & -- & -- \\
\hline $\begin{array}{l}\text { Total cholesterol by categories of } \\
\text { BMI }\end{array}$ & -- & -- & -- & $\begin{array}{c}0.95 \\
(0.92-0.99)\end{array}$ & -- & -- \\
\hline
\end{tabular}

Models were mutually adjusted

CI, Confidence interval; HR, Hazard ratio 


\section{Figure 1.}

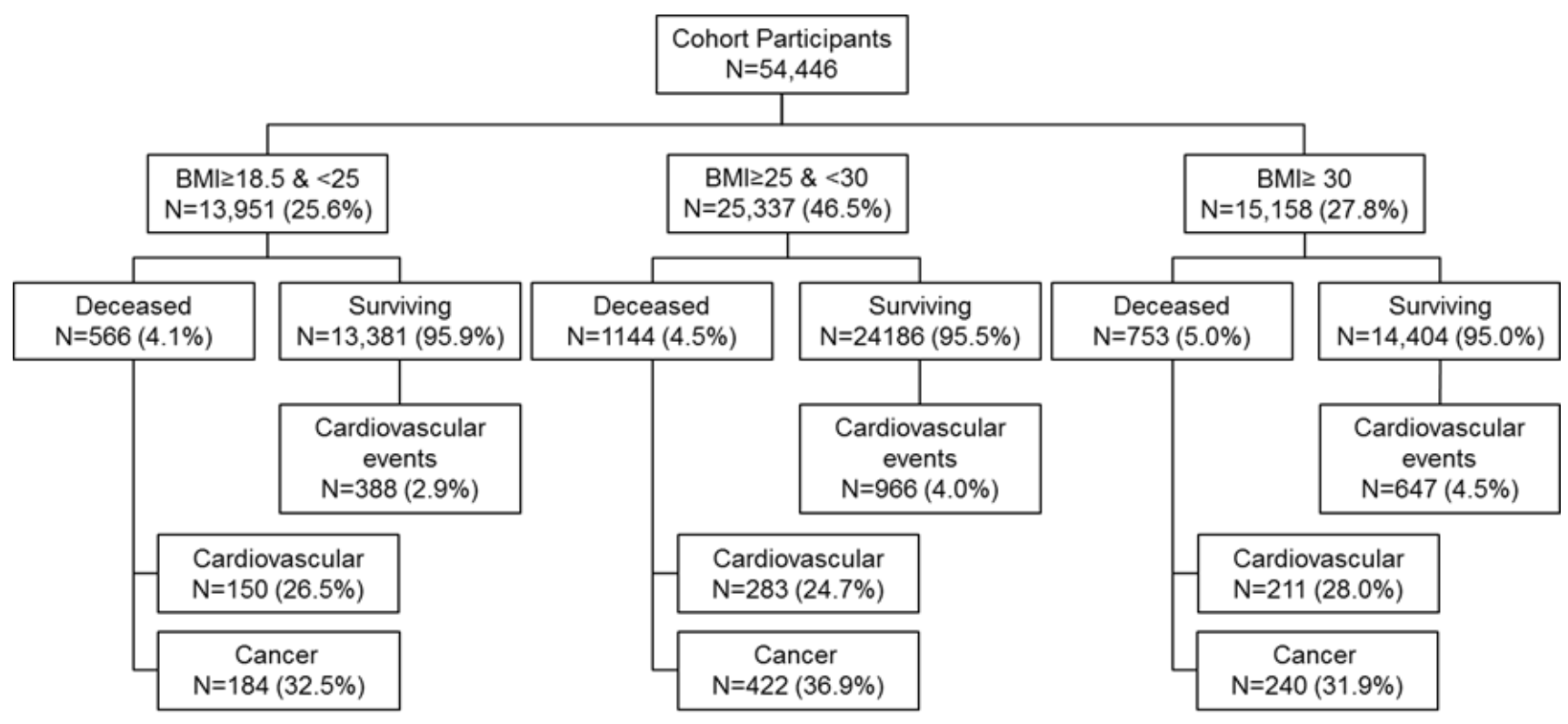


Figure 2.

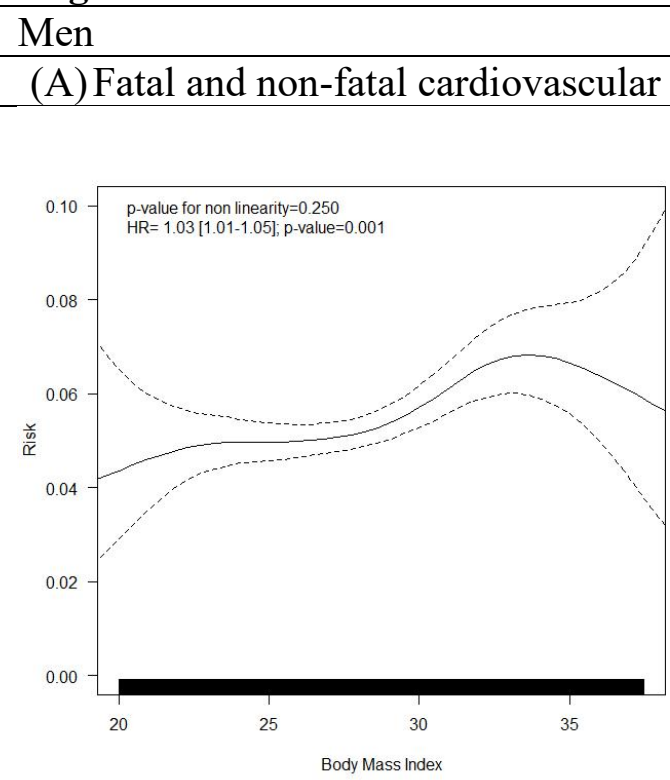

Women

incidence

(B) Cancer mortality
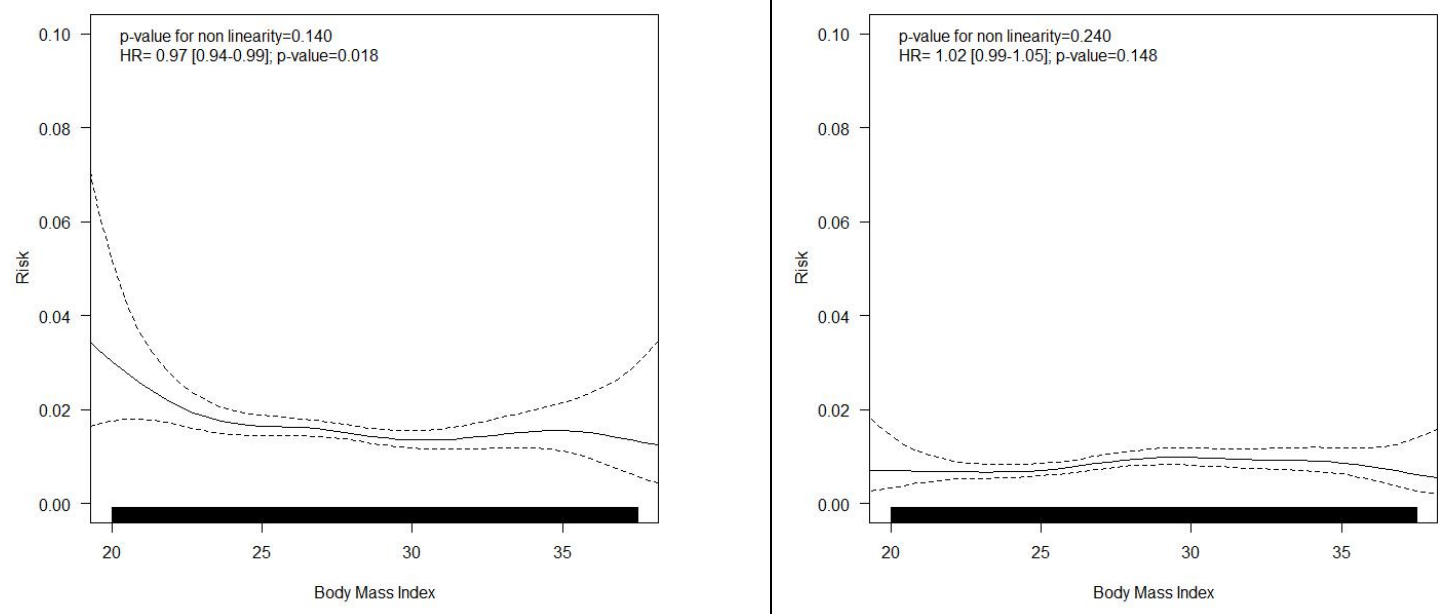

(C) Overall mortality
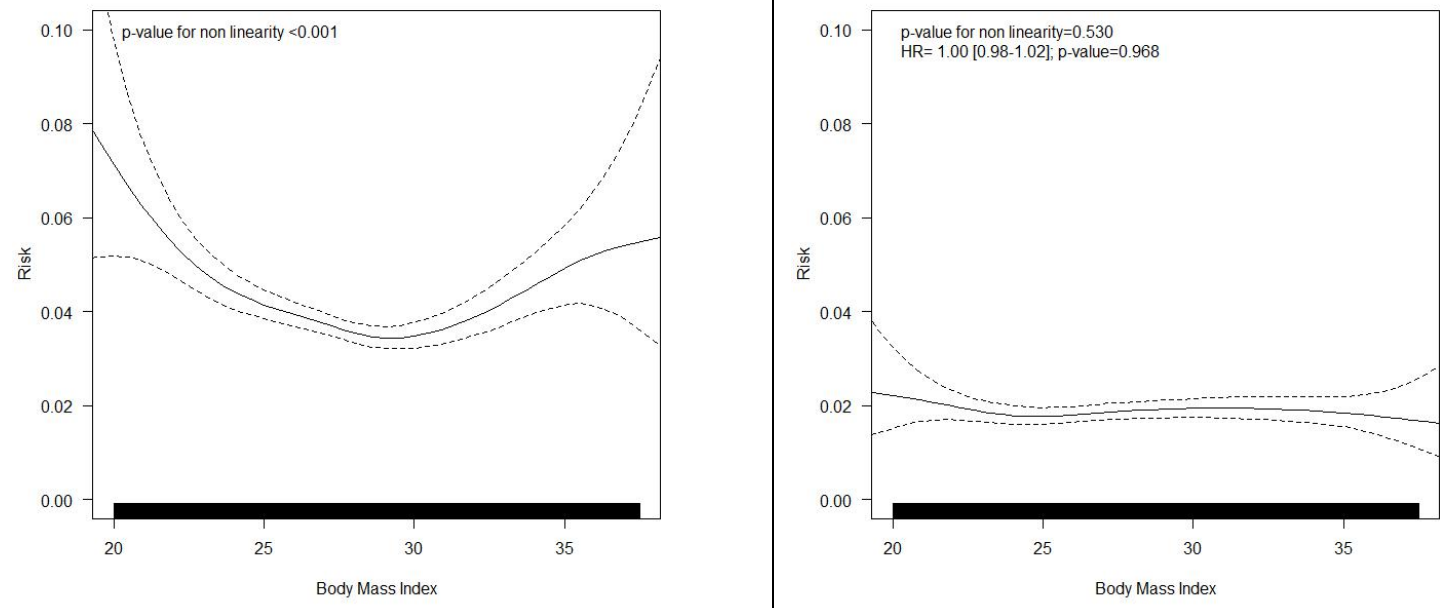
Figure 3.

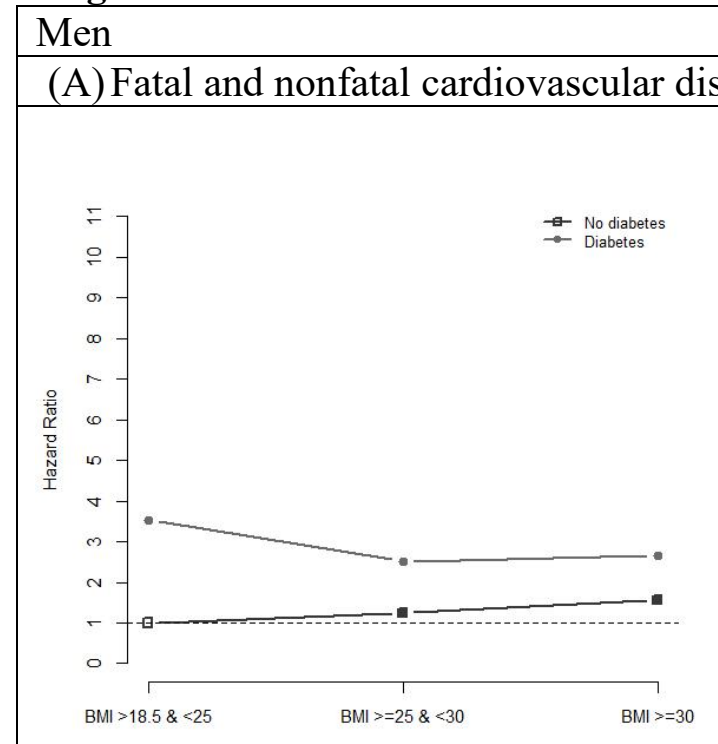

Women e incidence

(B) Cancer mortality

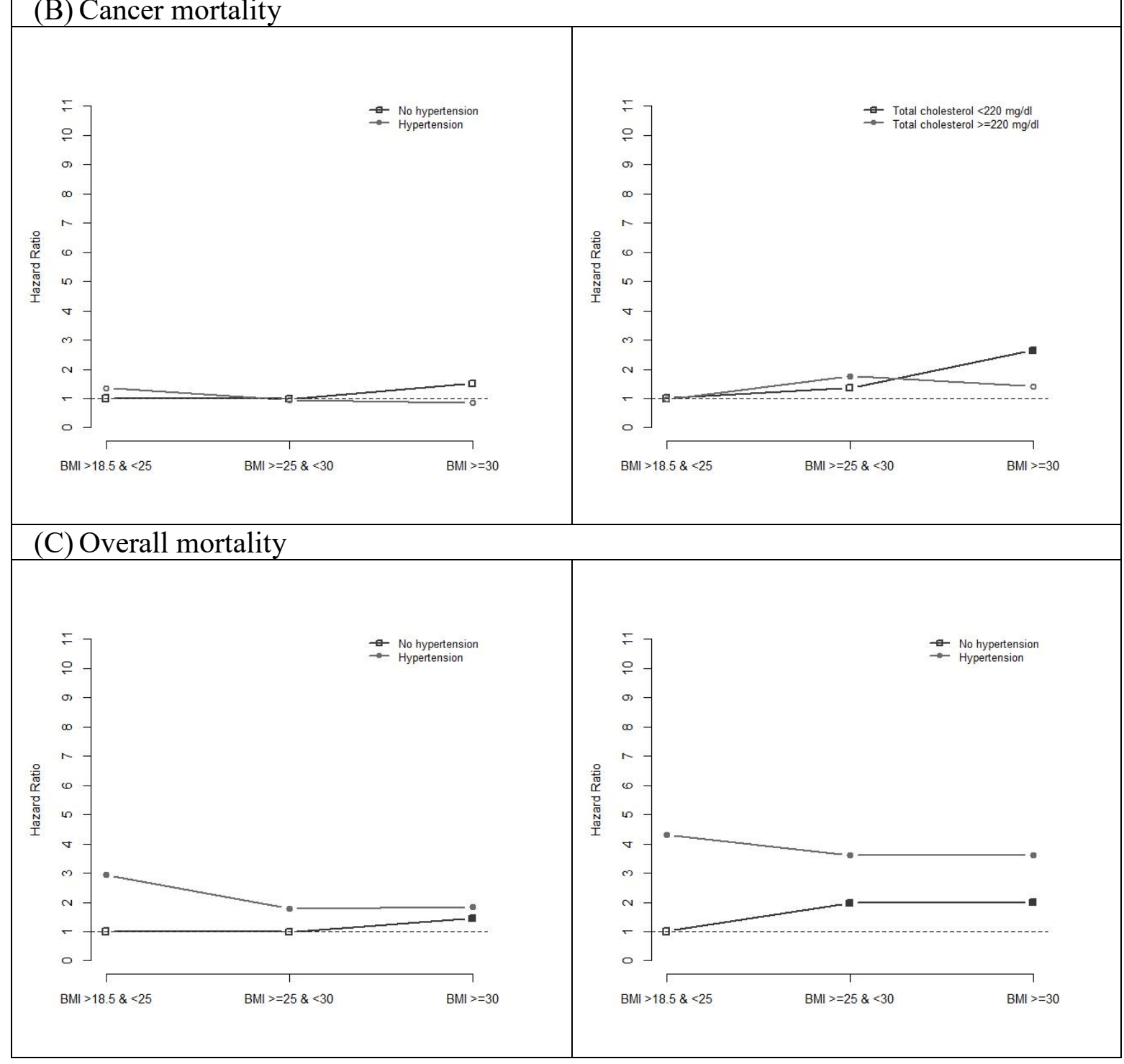

